\title{
EPIDEMIOLOGICAL STUDY OF LYME DISEASE IN BULGARIA
}

\author{
Neli Ermenlieva, Gabriela Tsankova, Tatina T. Todorova \\ Department of Microbiology and Virology, Faculty of Medicine, Medical University of Varna, Bulgaria
}

\section{SUMMARY}

Objectives: Lyme disease (Lyme borreliosis) is a transmissible infection, common in the temperate climate zones. It is caused by a group of spirochetal bacteria known as Borrelia burgdorferi sensu lato complex. The aim of the present work was to investigate the incidence rate of borreliosis in different regions of Bulgaria and to identify possible risk factors for its occurrence.

Methods: National and regional borreliosis incidence rates for 2009-2018 were obtained from the public database of the National Centre of Public Health and Analyses. Their association with some socio-demographic variables and the geographic location (south or north) of the regions was tested with Spearman's correlation analysis and simple linear regression.

Results: The mean annual incidence for the last 10 years (2009-2018) in Bulgaria was 6.9 (range 4.1-11.6) cases per 100,000 inhabitants. We found that the Lyme disease was highly fluctuating at regional level with incidence rates varied from 0.3 to 30.9 per 100,000 inhabitants. Several regions showed significantly higher endemicity for the disease. Socio-demographic factors were not found to be important for Lyme disease frequency while the geographic location in the north part of the country was a significant risk factor for it.

Conclusions: Lyme disease is a serious health risk in Bulgaria especially in its northern part - regions on the north are the most vulnerable to a higher incidence of the disease.

Key words: Lyme disease, ticks, epidemiology, incidence rates, geographic distribution

Address for correspondence: T. Todorova, Medical University of Varna, Faculty of Medicine, Department of Microbiology and Virology, 3, Bregalniza Str., 9002 Varna, Bulgaria. E-mail: Tatina.Todorova@mu-varna.bg

https://doi.org/10.21101/cejph.a5007

\section{INTRODUCTION}

Lyme disease (Lyme borreliosis) is a transmissible infection caused by a group of spirochetal bacteria known as Borrelia burgdorferi sensu lato complex. In Europe, the most common causes of Lyme disease are B. burgdoferi senso stricto, B. garini and B. afzelii which have different organotropism: $B$. afzelii is associated with skin manifestations; $B$. garinii - with encephalomyelitis; and $B$. burgdorferi sensu stricto with rheumatologic disorders $(1,2)$.

Lyme disease is the most common vector-borne disease in Europe, North America and Asia. At least 85,000 cases are registered each year in Europe, while in the United States their annual number varies between 15,000 and 20,000 (3). The disease is transmitted to human via tick's bite, mainly from species of genus Ixodes, which are the most important for the distribution of $B$. burgdorferi in nature (4). Important competent reservoirs of $B$. burgdorferi in Europe are common wild animals such as rodents, insectivores, hares and birds (3). Ticks can survive for more than three years and their spread is limited by environmental conditions (3) - the main climatic factors (temperature, humidity and landscape) strongly influence the distribution of ticks and their hosts. According to Semenza and Menne (5), higher temperature and increased annual rainfalls accelerate the ticks' developmental cycle, egg production and population distribution. Therefore, ecological factors determine the risk and frequency of human infection.
Actual information about the local and regional epidemiological patterns of Lyme disease in Bulgaria is missing. The existing knowledge of the association of geographic location (and since climatic conditions) with Lyme disease frequency in Bulgaria is also limited. Although nationally notifiable, borreliosis is rarely discussed in scientific literature and this prompts us to summarize its incidence rates in different parts of the country and to outline the regional profiles of the disease.

\section{MATERIALS AND METHODS}

Bulgaria is located in Southeastern Europe and consists of 28 administrative regions. The most important factor for climate formation is the central location of the Balkan Mountains which divide the country into northern and southern part. Most of northern Bulgaria has a temperate continental climate with cold winters and hot summers, while the climate in the southern part is more influenced by the Mediterranean Sea and has less significant temperature amplitude.

Data on national and regional borreliosis incidence rates for 2009-2018 were obtained from the public database of the National Centre of Public Health and Analyses. They were presented as a number of cases per 100,000 inhabitants. A set of selected socio-demographic variables (total population number, population density, proportion of rural population, and number of healthcare 
units per 10,000 persons) were extracted from the database of the National Statistical Institute and were tested as continuous variables for correlation with the incidence rates of Lyme disease in the regions. The method used was Spearman's rank correlation coefficient measurement. North/south location was used as a dichotomous variable in a simple linear regression model. Statistical analyses were performed using R v. 3.5.0 software (R Core Team, 2018). The statistical significance level was set at $5 \%$.

\section{RESULTS}

The average 10-year annual incidence of Lyme disease in Bulgaria for the last 10 years (2009-2018) was 6.9 with a range between 4.1 cases per 100,000 inhabitants in 2016 to 11.6 cases per 100,000 in 2009 (Fig. 1). Although approximately stable at national level, Lyme disease incidence was highly variable at regional level with average 10-year rates varied from 0.3 (region Kardzhali) to 30.9 (region Gabrovo) cases per 100,000 (Table 1, Fig. 2).

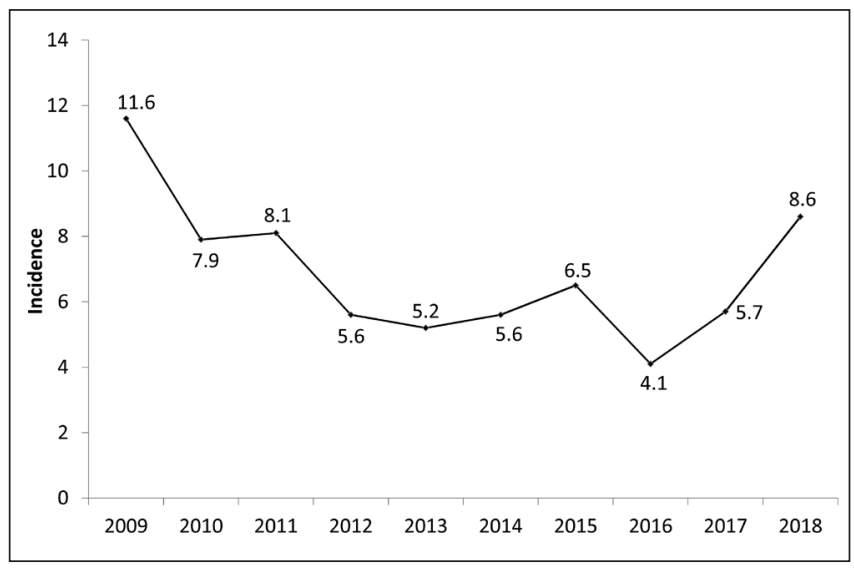

Fig. 1. Average annual incidence (cases per 100,000 inhabitants) of Lyme disease in Bulgaria (2009-2018).

Table 1. Incidence rates (number of cases per 100,000 population) for 2009-2018 in the regions of Bulgaria

\begin{tabular}{|c|c|c|c|c|c|c|c|c|c|c|c|}
\hline Region & 2009 & 2010 & 2011 & 2012 & 2013 & 2014 & 2015 & 2016 & 2017 & 2018 & Mean \\
\hline Blagoevgrad & 14.9 & 8.0 & 4.3 & 0.0 & 0.9 & 3.8 & 3.2 & 1.9 & 1.9 & 5.2 & 4.4 \\
\hline Burgas & 1.9 & 2.6 & 2.4 & 2.2 & 1.7 & 1.7 & 1.0 & 1.2 & 0.7 & 4.6 & 2.0 \\
\hline Varna & 18.3 & 18.3 & 14.8 & 12.0 & 9.9 & 7.0 & 6.3 & 6.1 & 5.7 & 7.9 & 10.6 \\
\hline V. Tarnovo & 17.7 & 5.9 & 9.3 & 3.5 & 1.2 & 1.6 & 7.3 & 3.3 & 7.5 & 5.1 & 6.3 \\
\hline Vidin & 0.9 & 1.9 & 0.0 & 0.0 & 1.0 & 1.1 & 2.2 & 3.3 & 1.1 & 3.5 & 1.5 \\
\hline Vratsa & 12.6 & 6.1 & 7.5 & 0.5 & 3.3 & 0.6 & 2.9 & 0.6 & 1.2 & 6.2 & 4.2 \\
\hline Gabrovo & 35.1 & 17.1 & 6.6 & 10.8 & 21.0 & 33.2 & 49.0 & 27.4 & 35.9 & 73.8 & 30.9 \\
\hline Dobrich & 11.0 & 18.6 & 29.6 & 31.0 & 8.6 & 8.7 & 19.4 & 9.5 & 11.8 & 17.3 & 16.5 \\
\hline Kardzhali & 0.0 & 0.0 & 0.0 & 0.0 & 0.7 & 0.7 & 0.0 & 0.0 & 0.7 & 0.7 & 0.3 \\
\hline Kyustendil & 2.7 & 0.0 & 0.7 & 0.0 & 0.0 & 0.8 & 0.8 & 1.6 & 0.8 & 3.4 & 1.1 \\
\hline Lovech & 3.3 & 0.7 & 0.0 & 0.7 & 10.2 & 7.4 & 8.4 & 4.6 & 9.4 & 21.6 & 6.6 \\
\hline Montana & 34.4 & 30.4 & 42.1 & 5.5 & 3.5 & 7.8 & 11.7 & 12.5 & 27.7 & 25.5 & 20.1 \\
\hline Pazardzhik & 0.7 & 0.7 & 0.4 & 0.4 & 0.0 & 0.4 & 0.4 & 0.4 & 0.4 & 0.4 & 0.4 \\
\hline Pernik & 21.9 & 12.5 & 21.1 & 11.4 & 10.8 & 11.7 & 8.0 & 6.4 & 13.8 & 31.4 & 14.9 \\
\hline Pleven & 14.7 & 2.1 & 8.2 & 12.5 & 10.3 & 8.9 & 10.3 & 9.6 & 10.2 & 12.1 & 9.9 \\
\hline Plovdiv & 4.3 & 1.6 & 3.4 & 4.3 & 3.5 & 6.6 & 4.8 & 4.2 & 3.1 & 3.6 & 3.9 \\
\hline Razgrad & 19.5 & 22.1 & 15.3 & 36.6 & 23.9 & 25 & 35.8 & 26.7 & 21.8 & 30.3 & 25.7 \\
\hline Ruse & 22.4 & 25.4 & 31.5 & 6.9 & 6.9 & 7.4 & 6.6 & 8.9 & 13.5 & 16.5 & 14.6 \\
\hline Silistra & 12.5 & 3.9 & 16.8 & 5.1 & 4.3 & 4.3 & 1.8 & 5.3 & 2.7 & 4.6 & 6.1 \\
\hline Sliven & 10.2 & 5.9 & 1.0 & 0.0 & 0.5 & 0.0 & 0.0 & 0.0 & 0.0 & 0.5 & 1.8 \\
\hline Smolyan & 0.0 & 0.8 & 0.0 & 0.8 & 0.0 & 4.3 & 1.8 & 0.9 & 2.8 & 1.9 & 1.3 \\
\hline Sofia City & 5.7 & 3.5 & 1.9 & 1.3 & 5.1 & 5.4 & 6.7 & 1.3 & 5.8 & 7.5 & 4.4 \\
\hline Sofia Pr. & 3.9 & 1.2 & 0.4 & 0.4 & 0.8 & 2.1 & 1.3 & 0.4 & 0.9 & 0.0 & 1.1 \\
\hline Stara Zagora & 24.7 & 15.8 & 10.2 & 6.4 & 4.0 & 4.0 & 3.4 & 1.9 & 3.1 & 8.9 & 8.2 \\
\hline Targovishte & 40.6 & 31.8 & 26.6 & 38.6 & 27.9 & 13.7 & 20.8 & 10.5 & 4.4 & 15.2 & 22.9 \\
\hline Haskovo & 20.2 & 5.5 & 8.2 & 2.5 & 2.9 & 4.2 & 4.2 & 2.1 & 3.9 & 3.5 & 5.7 \\
\hline Shumen & 11.8 & 14.5 & 14.4 & 10.0 & 6.7 & 6.2 & 7.4 & 2.9 & 2.9 & 2.3 & 7.9 \\
\hline Yambol & 10.0 & 3.6 & 6.9 & 0.8 & 0.8 & 0.8 & 0.0 & 0.0 & 0.0 & 0.8 & 2.4 \\
\hline Total & 11.6 & 7.9 & 8.1 & 5.6 & 5.2 & 5.6 & 6.5 & 4.1 & 5.7 & 8.6 & 6.9 \\
\hline
\end{tabular}




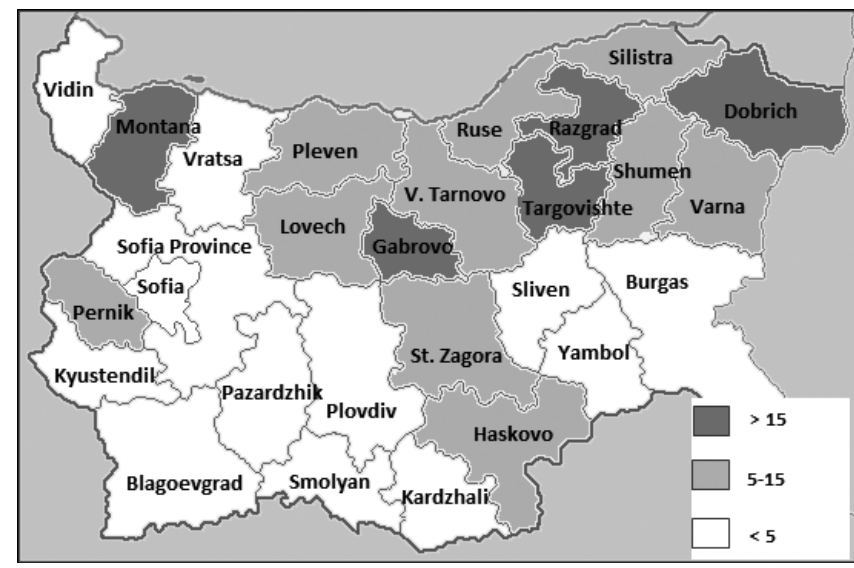

Fig. 2. Spatial distribution of Lyme disease in Bulgaria (mean 10-year annual incidence rates per 100,000).

Table 2. Spearman's rank correlation coefficients $\left(r_{s}\right)$ between the mean 10-year incidence of Lyme disease and selected socio-demographic predictors

\begin{tabular}{|l|c|c|}
\hline Potential risk factors & $\mathrm{r}_{\mathrm{s}}$ & $\mathrm{p}$-value \\
\hline Total population number & -0.11 & 0.56 \\
\hline Population density $\left(\right.$ per $\left.\mathrm{km}^{2}\right)$ & 0.21 & 0.26 \\
\hline Proportion of rural population (\%) & -0.31 & 0.11 \\
\hline Number of healthcare units per 10,000 persons & 0.14 & 0.48 \\
\hline
\end{tabular}

To test for possible association between regional sociodemographic characteristics and Lyme disease incidence, we performed a correlation analysis. The borreliosis frequency did not associate with the total population number and the population density of the corresponding regions - the Spearman's rank correlation coefficients were -0.11 and 0.21 , respectively (Table 2). The proportion of rural population (used as indirect determinant of the population involved in agriculture) and the number of healthcare units in each region (used as determinant of health care access) were also not related to the frequency of Lyme disease (Table 2). The only factor that seems to have importance is the northern location of the region - in linear regression model, north localization determined an average difference of 9.4 in the incidence rate between northern and southern regions (coefficient $\beta=9.4$, std. error $=2.6, p=0.001$ ).

\section{DISCUSSION}

In the present analysis, we found that the average national incidence rate of Lyme disease cases in Bulgaria for the last 10 years (2009-2018) was 6.9. This number is consistent with other national reports, which found annual incidence rates between 4 and 12 cases per 100,000 individuals (6-8). The incidence of Lyme disease in Bulgaria is comparable to that of the neighbour countries - Romania has a mean incidence rate of 2.1 per 100,000 population (9) and Serbia 10.7 (10).

The transmission of an infectious disease is determined by many factors, including social, economic and ecological conditions, such as population density, access to health care, climate, contact with wild animals, and intrinsic human immunity (5). An association (measured as Spearman's rank correlation coefficients) between borreliosis frequency and population-related socio-demographic factors, such as total population number and population density of the corresponding regions was not significant - finding that can be easily explained by the fact that Lyme disease is a zoonosis and human to human transmission is not involved in the spread of the infection.

Agriculture is an important risk factor for Lyme disease occurrence, as it brings people in close contact with ticks and other vectors, accordingly most of the infected individuals in Bulgaria are persons employed in farming (7). Agriculture in Bulgaria is fragmented and requires more manual labour and thus the risk of infection increases. In addition, insufficient and irregular usage of acaricides (tick pesticides) helps maintain a high epidemic potential. Surprisingly, the proportion of the rural population (used as indirect determinant of the population involved in agriculture) was also not related to the frequency of Lyme disease (Table 2).

Borreliosis is a challenging diagnosis, especially when no tick's bite is reported by the patient and it is possible that available healthcare facilities and modern diagnostic tools influence the rate of disease notification in each region. This was not the case as the reported regional incidences did not depend on the number of healthcare units in each region (Table 2).

As shown in Table 1, several regions as Gabrovo, Razgrad, Targovishte, Montana, and Dobrich showed significantly higher endemicity for the disease. These regions are located in the northern part of the country, while Kardzhali and Pazardzhik (located in the southern part of the country) reported a negligible number of cases during the period of the study. This fact prompted the hypothesis that northern location of the region is a significant factor for higher borreliosis incidence - indeed the simple linear regression model showed that the incidence rates in northern regions were approximately 9.4 higher than the incidence rates in southern regions. A similar decreasing gradient of incidence from north to south is observed in other countries in South Europe (Greece, Italy and Spain) (3). The continental character of the climate in northern Bulgaria is influenced by the air transfer from the north-west. This air mass reaches the western part of the Balkan Mountains and causes significant precipitation. When it passes through the ridge of the mountains, it is considerably less moist, and the rainfall amount is smaller in southern Bulgaria. Drought is a factor that negatively affects the processes of reproduction of tick population. In addition, the rainfall maximum on the north is during the month of June (a season favourable for tick's reproduction), while in southern Bulgaria heavy rain precipitation is typical during the winter months. Therefore, in northern Bulgaria, the environmental conditions favour development of the tick populations and active dissemination of tick infections including Lyme disease.

\section{CONCLUSION}

It is evident that the incidence rates of Lyme disease vary significantly among the small territory of Bulgaria and the disease represents a serious health risk in the country especially in its northern part - regions Gabrovo, Razgrad, Targoviste, Montana, and Dobrich are the most vulnerable to a higher incidence of 
Lyme borreliosis. We hypothesized that this higher incidence is mainly due to climatic factors (especially humid spring and summer months typical for the northern part of Bulgaria). An effective preventive programme as well as deeper knowledge on the distribution of both pathogen and vector in different geographic regions are increasingly needed.

\section{Conflict of Interests}

None declared

\section{REFERENCES}

1. Parola P, Raoult D. Tick-borne bacterial diseases emerging in Europe. Clin Microbiol Infect. 2001;7(2):80-3.

2. Socolovschi C, Mediannikov O, Raoult D, Parola P. Update on tick-borne bacterial diseases in Europe. Parasite. 2009;16(4):259-73.

3. Lindgren E, Jaenson TGT. Lyme borreliosis in Europe: influences of climate and climate change, epidemiology, ecology and adaptation measures. Geneva: WHO; 2006.

4. Pepin KM, Eisen RJ, Mead PS, Piesman J, Fish D, Hoen AG, et al. Geographic variation in the relationship between human Lyme disease incidence and density of infected host-seeking Ixodes scapularis nymphs in the Eastern United States. Am J Trop Med Hyg. 2012 Jun;86(6):106271.

5. Semenza JC, Menne B. Climate change and infectious diseases in Europe. Lancet Infect Dis. 2009;9(6):365-75

6. Christova I, Schouls L, van De Pol I, Park J, Panayotov S, Lefterova V, et al. High prevalence of granulocytic Ehrlichiae and Borrelia burgdorferi Sensu Lato in Ixodes ricinus ticks from Bulgaria. J Clin Microbiol. 2001;39(11):4172-4

7. Doycheva V, Dimitrova T, Odiseev H. Lyme disease - an important medical problem. Gen Med. 2009;11(2):28-30.

8. Christova I. Vector-borne infections in Bulgaria. In: Savic S, editor. Vectors and vector-borne zoonotic diseases. London: IntechOpen; 2019.

9. Raileanu C, Moutailler S, Pavel I, Porea D, Mihalca AD, Savuta G, et al. Borrelia diversity and co-infection with other tick borne pathogens in ticks. Front Cell Infect Microbiol. 2017 Feb 14;7:36. doi: 10.3389/ fcimb.2017.00036.

10. Krstić M, Stajković N, Lazić S. Prevalence of Borrelia burgdorferi sensu lato in Ixodes ricinus ticks and assessment of entomological risk index at localities in Belgrade. Vojnosanit Pregl. 2016;73(9):817-24.

Received December 12, 2016 Accepted in revised form June 25, 2019 